\title{
Discussion to the paper by M. H. Irving
}

GRUBER. Would you comment on the work which showed that acidosis was able to increase cardiac output? If the data are examined carefully one notices that the patients actually had very slight metabolic acidosis, and most of them were on a respirator already. I don't think you can generalize and say that acidosis is good.

IRVING. The paper by Andersen \& Mouritzen (1966) was an experimental study, and was one of the more careful studies on the effects of acidosis in experimental shock. There are other references showing that acidosis is of no great harm. I do not feel that when man under stress, such as exercise, develops a pH of 6.97 and a lactic acidosis of $22 \mathrm{mEq} / \mathrm{l}$, this could be an environment deleterious to myocardial function.

SCHRÖDER. We have recently investigated a patient with lactic acidosis of unknown origin with lactic acid levels over $25 \mathrm{mEq} / 1$, who had a $\mathrm{pH}$ of 6.87 and a cardiac output of $9 \mathrm{l} / \mathrm{min}$. She was given large doses of bicarbonate and the cardiac output did not rise. Bicarbonate was then stopped and haemodialysis started and over 36 $\mathrm{hr}$ there was a $\mathrm{pH}$ in the range of 7 , and the cardiac output did not drop below $6 \mathrm{l} / \mathrm{min}$. There was a low peripheral resistance and a relatively low blood pressure, but the cardiac output all the time was very good, with a very low $\mathrm{pH}$.

IRVING. In our experimental animals the heart went on beating for $3 \mathrm{hr}$ with lactic acid levels of $15-20 \mathrm{mEq} / \mathrm{l}$, and at no time did the myocardium show any embarrassment.

WALDER. When we talk about protection at the receptor level, we are referring to receptors on the smooth muscle of the blood vessels. The lactic acid is presumably coming from the striped fibres of skeletal muscle and not from smooth muscle in the blood vessels. The lactic acid comes from the muscle masses because of a combination of anoxia plus adrenaline. These two factors lead to anaerobic metabolism, and the production of lactic acid. If you then use a $\beta$-blocker and prevent vasodilatation, you may reduce the blood flow through the muscle but this will lead to more anoxia and the production of more lactic acid. Similarly with vasoconstrictor drugs.

McGowAN. You have produced a theory that total adrenergic blockade is beneficial in shock, but I can quote a number of papers which claim to show that noradrenaline is extremely valuable in the treatment of shock. Your experiments have shown a protective action of total adrenergic blockade; this has been shown for a large number of drugs, but most of them have turned out not to be valuable in the treatment of shock. There are plenty of ways of preventing experimental shock but very few ways of treating it successfully.

IRVING. I agree this has no therapeutic action whatsoever in its present form. It might possibly have application in patients in whom you produce a high catecholamine state, for example in cardiac bypass, where the effects could be prevented by premedication.
Hoffbrand. The dog has done a great disservice to man by being so readily available for work in this field. It is largely as a result of experiments in the dog that we are talking today about such concepts as universal endotoxaemia, adrenergic hyperactivity and irreversible shock itself, when many people would doubt whether the latter exists in man. There is a vast amount of controversy as to whether these earlier two concepts really hold in the dog, and extrapolating, as some have done with great enthusiasm, notably Lillehei, from dog to man is open to danger.

We have been working on yet another species, the unanaesthetized rhesus monkey, uncomplicated by recent surgery. We have noted great differences between the clinical situations in haemorrhagic shock and endotoxin shock. Both are identical terminally in the dog, but they are not so in man or in the monkey. In haemorrhagic shock there is a considerable redistribution of blood: vasodilatation in the heart, brain, adrenals and jejunum, and vasoconstriction in skin, pancreas and muscle. In endotoxin shock there is a very different picture, which is very much against universal endotoxaemia being responsible for the circulatory changes. There is a fall in totab peripheral resistance (TPR) as in the vasodilated, early septic shock in man. Even terminally, there is widespreats vasodilatation in all organs and very little vasoconstric? tion, and this is a powerful argument against the concept of adrenergic over-activity being responsible.

WRIGHT. Did you measure blood glucose and see the effect of blockade?

IRVING. In $\alpha$-blockade there was no difference from the control animals, in $\beta$-blockade they tended toward hypoglycaemia, and in combined $\alpha$ - and $\beta$-blockade they behaved as normal animals as regards blood glucose levels (Halmagyi, Irving \& Varga, 1968).

There were many side effects which I have not dealt with: the prevention of ileus by $\alpha$-blockade, the prevention of anuria by $\beta$-blockade. The normal rise in plasma osmolality was prevented by combined blockade, as was hypercoagulability.

WiLson. The postulated enzyme substrate complex presumably must exist in all cells if the hormones are using ATP as substrate. Many hormones have some effect on ATP and the effect varies according to the dose level of the hormone. You can only work out what is happening by doing cytological and cytochemical studies. Comparative studies on the cytochemical level might also show which is the best animal to use in experiments on shock or whether it is necessary to use man.

HopkIN. Shock is a defensive mechanism common to the whole animal world. Even the rabbit and the guineapig have their defensive mechanisms and it is reasonable to suppose that the same basic mechanisms have been handed down in evolution. The most obvious way for this to operate in an animal is through the central nervous system. Assuming that the circulatory and metabolic 
responses to injury known as 'shock' are neurogenic in origin, perhaps a better approach to prevention and treatment would be to attempt to block or reduce the intensity of stimuli entering the central nervous system, rather than by trying to blockade the resulting sympathetic responses. There is some evidence that chlorpromazine reduces the activating influence of incoming stimuli to the brain stem (Bradley, 1963).

\section{References}

Andersen, M.N. \& Mouritzen, C. (1966) Effect of acute respiratory and metabolic acidosis on cardiac output and peripheral resistance. Ann. Surg. 163, 161.

Bradley, P.B. (1963) Reticular Formation of the Brain Stem. Churchill, London.

Halmagyi, D.F.J., IRving, M.H. \& VARGA, D. (1968) Effect of adrenergic blockade on the metabolic response to hemorrhagic shock. J. appl. Physiol. 25, 384. 